\section{Planning Families}

1968 has been designated Human Rights Year by the United Nations, and the International Planned Parenthood Federation (IPPF) has responded enthusiastically to the call. The federation, fortified by the belief that knowledge of contraception is a fundamental human right, has just announced that the estimated expenditure for 1968 is over $£ 2$ million, double the 1967 figure. Voluntary associations for family planning in fifty countries make up the federation, with support from the governments of Britain, Sweden, Denmark, Holland, Norway and the USA, as well as charitable institutions. During the coming year effort will be concentrated in areas where there are no government supported programmes, particularly in Latin America, where population is growing faster than in Asia, despite high abortion rates. If the present growth rate continues, the population of India will have trebled in under 50 years, while that of Brazil will have quadrupled.

It is hoped that sufficient funds will be raised to make individual grants to twenty-one Latin American countries, the largest going to Brazil, to equip clinics and train personnel, as well as to provide education programmes which are essential if the schemes are to be successful. Mobile clinics are planned for various parts of the world, particularly in Kenya and West Africa, and-the nicest touch of all-a riverboat will take family planning to communities round the waterways of East Pakistan. The Indian offer of money for men willing to be sterilized has sometimes been described as bribery, but last week Lady Rama Rau, president of IPPF, said the benefit-only about $£ 1$-is given to make up for the lack of hospital facilities.

As well as work on a practical level, the IPPF finances a Basic Sciences Committee to discuss and evaluate the laboratory research which is in progress on the various aspects of human reproduction and its prevention. Professor A. S. Parkes, formerly professor of physiology of reproduction at Cambridge University, has been appointed chairman of this committee. Two new groups of specialists have been established to cover educational matters. One will investigate family planning in the teaching of doctors and nurses, and the other will advise on the best methods of bringing knowledge of family planning to organizations and individuals in different parts of the world.

\section{Human Development}

A CENTRE for Advanced Study in the Developmental Sciences is being established near Oxford, for the promotion of interdisciplinary communication and. growth of knowledge in the behavioural sciences. Dr A. Ambrose, formerly at the Tavistock Institute and now director of the centre, has been largely responsible for the project from its beginnings, and has donated Minster Lovell Mill which will house the centre in 1969. By providing a specialized library and facilities for study groups, individual study and short courses, the centre will allow specialists from all parts of the world and from all disciplines to meet and exchange ideas on human development and the factors which are likely to cause deviation from normal behaviour. No basic research will be carried out at Minster Lovell, but fellowships will be awarded for research to be carried out wherever suitable material is available. Proceedings of study group discussions will be published to bring the cross-fertilization of ideas to a wider audience.

Considerable building and alteration work is being done at the mill to provide accommodation for 30 people, as well as a library and conference rooms, but meanwhile the centre is beginning its scientific activities in accommodation provided by the Ciba Foundation in London. The first study group is being held this week on the functions of stimulation in early postnatal development, and is being attended by 15 people from all parts of the world. The centre, which will be controlled by a specially set up Developmental Sciences Trust, will be managed by an executive council consisting of Professor Brian Foss, Dr Ronald Mackeith, Mr John Marsh, Dr Christopher Ounsted and Dr Gordon Wolstenholme. The scientific advisory panel, constituted on an international basis, includes Dr J. Bowlby, Professor M. Abercrombie, Professor R. Hinde, Dr E. Leach, Professor J. Tanner and Professor N. Tinbergen. An appeal will be launched in the spring to raise $£ 0.5$ million which will be required to run the centre for five years.

\section{Stopping Supertankers}

As tankers get larger and larger, so does the problem of stopping them. Dr Hatsuko Tani, of the Tokyo University of Mercantile Marine, discussed the problem in a paper presented to the Institute of Navigation on November 15. Dr Tani discussed three ways of avoiding obstacles; putting the helm hard over, reversing the engines, or doing both at once. Until twenty years ago, he said, the distance needed for a ship to come to a stop in a straight line with the engines full astern was comparable with the forward distance travelled if the helm were put hard over. The distance in the first case is called the head reach, and in the secord is called the turning advance. For a modern tanker weighing 100,000 tons, on the other hand, the head reach is between ten and fifteen times the length of the ship, while the turning advance is only five to seven times the length. This slightly surprising result comes about because the mass of the ship-and hence the inertial forces-increases with the cube of the length, while the total resistance of the hull underwater increases with the square of the length.

From the captain's point of view, it is vital to know how soon the ship can be stopped, both for everyday activities like picking up pilots, anchoring and berthing, or for emergencies like avoiding collisions or going aground. Dr Tani described theoretical studies which enable calculations of the head reach to be made. To make the problem even easier, he plotted the figures on a diagram. Comparison of the theoretical results with experience on two large supertankers and a medium size tanker (the Esso Suez) had shown that the calculations produced the right answer to a very fair degree of accuracy.

But this takes no account of the third possibilitythat of reversing the engines and putting the helm hard across at the same time. The distance taken to stop in this case Dr Tani calls the stopping advance, and it depends on speed, as well as the other sailing characteristics of the ship. Turning advance, on the other hand, is virtually constant within the normal speed 
range, and depends only on the rudder angle and not on the speed. At high speeds, therefore, the turning advance is smaller than the stopping advance; as speeds falls, the two become identical, and at low speed stopping advance is the shorter of the two. (This takes no account of the tendency of the ship to behave irrationally when the rudder is hard over and the propellers reversing. Occasionally under these conditions ships make sharp turns, often to starboard, either because of the unbalancing effect of the righthanded screw propeller, or, in Dr Tani's opinion, because the course stability of the ship becomes extremely poor.)

What conclusions can the captain draw from these unexpectedly complicated considerations ? At high speed, a full rudder turn is probably the best course, without reversing the engines. At lower speed, reversing the engines and putting the helm hard over may be best. If the object to be avoided is approachingas, for example, in a collision situation-the important criterion is to reduce speed in as short a time as possible; in this case, although the ship may be travelling above the critical speed, a crash-back procedure with engines in reverse is recommended.

\section{Saturn Aloft}

\section{from a Correspondent}

LAST week's first Saturn V flight (called Apollo 4) may have helped NASA to catch up on the lagging timetable for landing two Americans on the Moon by 1970. By combining in one flight the first operational tests of several important components, time has been saved and many of the tactical obstacles to the first manned flight in the Apollo capsule cleared away. That flight is now fixed for autumn 1968, employing the less powerful Saturn I as booster for a low Earth orbit to check the capsule under "live" conditions. At least three further steps of graduated difficulty must follow before the lunar landing attempt.

There is no doubt of the technological achievement of the first Saturn V flight, however misplaced or outdated may now seem the goal of a manned Moon landing by 1970. The organization and co-ordination by themselves compare with an important military exercise-with far less margin for improvization. That the launching took place to the minute- -0700 hours local time, October 8--marks the planning efficiency and the soundness of the new Moonport Complex 39 at its first launching.

The chief engineering tasks to be met were these. The unflown first stage (F 1), presumed the biggest booster ever to take off, used conventional fuel, but to concentrate a thrust building up to 8.5 million pounds within 150 seconds depended on the fine adjustment and balance of the supply of 28,000 pounds-per-second of propellant for simultaneous burning in five matched engines. The second stage, delivering one million pounds, had never flown before and used tricky liquid hydrogen as propellant in its five clustered $(J-2)$ engines. To ensure smooth transfer of power between stages, eight solid fuel rockets used for stage separation also had to "settle" the super-cooled liquids in the bottom of their tanks to ensure instant feed under high vacuum and weightlessness. The thind stage centred on a single liquid hydrogen $J-2$ engine, with fourteen other rockets for ancillary purposes. The critical and pre- viously untried test for this stage was to restart the main engine after two Earth orbits to push the vehicle out to a distance $(9,300$ nautical miles) whence it could start a simulated lunar return and re-entry to prove the Apollo capsule's heat shield. This involved accelerating it downward by means of further rocket burns and high precision onboard control only partly prompted from the ground to ensure correct attitude, angle and so on, to narrow margins for the high speed collision with the atmosphere. A glancing blow, $7.13^{\circ}$ (to local horizontal), on the heat protected blunt forward end of the spacecraft was called for, and achieved.

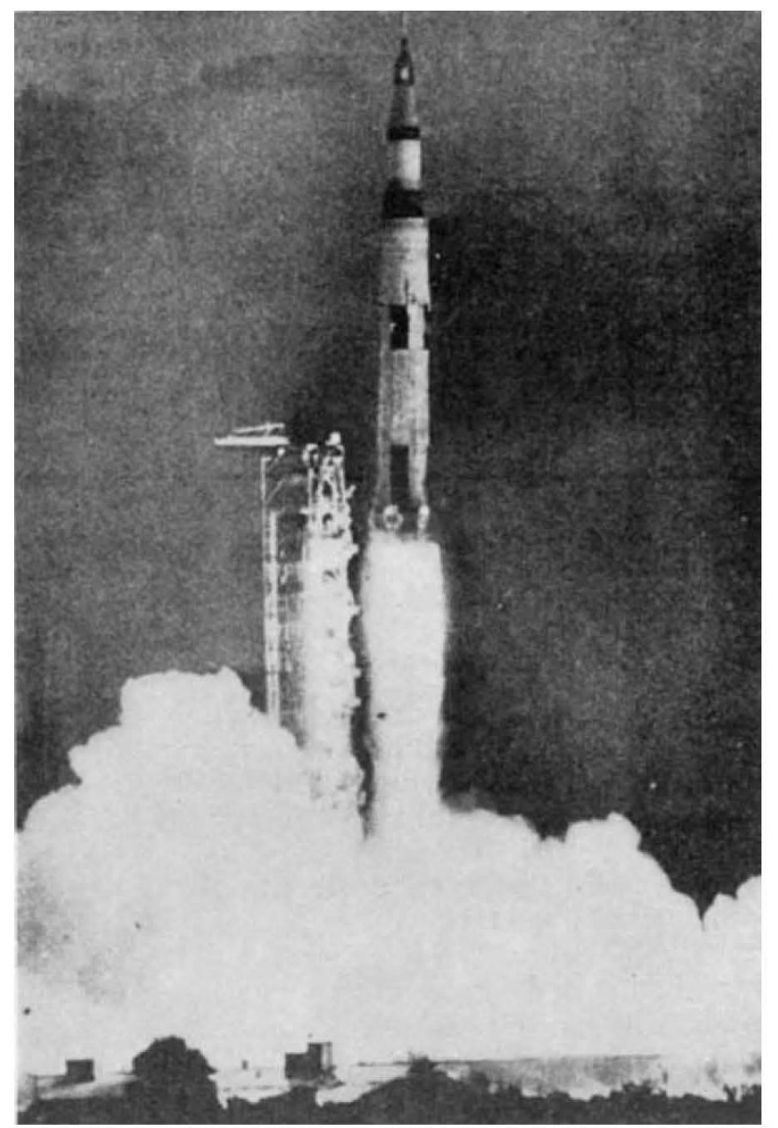

\section{More Action on Aldabra}

Convincen that Aldabra Atoll should be preserved entire without the air staging post which the Ministry of Defence wants, the Royal Society has made a further approach to the Secretary of State for Defence. Since its last approach in May, the society has reappraised the case in the light of the results of the preliminary ecological survey of the atoll and of recent modifications to the defence proposals. These proposals would limit any development, if and when a decision is taken, to the eastern end of the south island, instead of involving all the islands of the atoll as originally planned.

The Royal Society has repeated that any development on Aldabra will upset the integral ecosystem, which is the great scientific interest of this, the last remaining ecosystem of its kind in the Indian Ocean. Confining the air staging post to one part of one island will not save the ecosystem. It would not be possible 